\title{
Langmuir films study on lipid-containing artificial tears
}

\author{
J. Torrent-Burgués \\ Department of Chemical Engineering, School of Optics and Optometry, \\ Universitat Politècnica de Catalunya (UPC), \\ C/ Colom 1, 08222 Terrassa (Barcelona), Spain \\ e-mail: juan.torrent@upc.edu, Tlf: +34 937398043
}

\section{(SHORT COMMUNICATION)}

\begin{abstract}
Lipid-containing artificial tears are a type of artificial tears that use lipid components in order to restore the lipid layer of the tear film. One of these components is lecithin which can be applied in spray solutions containing lecithin liposomes. In this work the behavior of three of these commercial tears based on lecithin, Innoxa, Opticalm and Optrex, are studied using the Langmuir technique. The obtained isotherms are presented, discussed and compared. This technique seems useful in order to see the film behavior of the lipid components of these tears and determine some important parameters such as fluidity and extension at the air-water interface, and allows us to discern differences between these commercial tears. Innoxa and Optrex tears are more similar to each other than to Opticalm tears. Opticalm presents more fluidity, probably due to the presence of more insaturations in the fatty acid chains of the phospholipids of the lecithin used in fabrication.
\end{abstract}

\section{Keywords}

Lipid-containing artificial tears, lecithin, Langmuir film, isotherm, compressibility modulus

\section{Introduction}

The use of artificial tears is related with dry eye problems or ocular irritations [1-3]. Different types of artificial tears exist [4-6] and several studies have been reported on them [7-15]. One type of them is the lipid-containing artificial tears which help to 
repair or improve the lipid layer present in the outermost part of the tear film, and some studies have been reported in literature [7, 16-18]. In these studies the artificial tears are used as eye drops. Several lipid-containing artificial tears are present on the market and commercialised by several companies. In the composition of some of these lipid-containing tears a phospholipid component (lecithin of soya), which is composed mainly of phospholipids such as phosphocholine (also named phosphatidylcholine or PC) occurs as a principal item. Lecithin of soya is obtained from soya grains by mechanical extraction or chemically using hexane. It has a high content of PC, especially refined lecithin, but also other lipids are present. The fatty acid chains present in these PCs are mainly palmitic or stearic, in C1, and oleic or linoleic, in C2. Refined lecithin is used mostly for pharmaceutical applications and research. In commercial lipid-containing artificial tears others components are also present.

The film formation at the water/air interface (Langmuir film technique) has been applied to study the behaviour of Meibomian lipids [19-23] and especially to study the interaction of them with lachrymal proteins [24-27]. The Langmuir technique has been applied previously by the author to study the behaviour of lipid and phospholipid films $[28,29]$. In this work Langmuir films have been obtained from lipid-containing artificial tears and the corresponding surface pressure-area isotherms registered. Three commercial lipid-containing artificial tears have been used, Innoxa, Opticalm and Optrex, the composition of which is shown in Table 1. These tears are supplied in little bottles for liposomal ocular spray applications. To the knowledge of the author, it is the first time that a Langmuir film study has been performed on lipid-containing artificial tears supplied as sprays.

\section{Materials and methods}

\subsection{Materials}

Commercial lipid-containing tears are those of Innoxa (Manufacturer: Optima Pharmazeutische GmbH, Distributor: Omega Pharma España), Opticalm (Manufacturer: Medena AG, Distributor: Omega Pharma) and Optrex (Manufacturer: Optima Medical Swiss AG, Distributor: Reckitt Benckiser Healthcare). Their composition is indicated below (Table 1). It is seen that a priori the composition of all the products is the same or similar. These products are supplied as ocular sprays. 
Water was ultrapure Milli-Q $(18.2 \mathrm{M} \Omega \cdot \mathrm{cm}), \mathrm{NaCl}$ and chloroform were of analytical grade.

Table 1. Composition of three commercial lipid-containing artificial tears.

\begin{tabular}{|l|l|l|l|}
\hline Composition in $1 \mathrm{~mL}$ & Innoxa (Optimyst) & Opticalm (Lipomyst) & Optrex (Actimist) \\
\hline Lecithin of soya & $10 \mathrm{mg}$ & $10 \mathrm{mg}$ & $10 \mathrm{mg}$ \\
\hline Sodium chloride & $8 \mathrm{mg}$ & $2.8 \mathrm{mg}$ & $8 \mathrm{mg}$ \\
\hline Ethanol & $8 \mathrm{mg}$ & $8 \mathrm{mg}$ & $8 \mathrm{mg}$ \\
\hline Phenoxyethanol & $5 \mathrm{mg}$ & - & $5 \mathrm{mg}$ \\
\hline Vitamin A-palmitate & $0.25 \mathrm{mg}$ & $0.25 \mathrm{mg}$ & $0.25 \mathrm{mg}$ \\
\hline Vitamin E & $0.02 \mathrm{mg}$ & $0.02 \mathrm{mg}$ & $0.02 \mathrm{mg}$ \\
\hline Purified water & & & \\
\hline
\end{tabular}

\subsection{Techniques and equipment}

The isotherm experiments have been done in a NIMA Teflon trough, model 1232D1D2 (area $1200 \mathrm{~cm}^{2}$ ), with two movable barriers and using a Wilhelmy plate to measure the surface pressure. The linear velocity of the barriers was $2.5 \mathrm{~cm} / \mathrm{min}$, which mean $50 \mathrm{~cm}^{2} / \mathrm{min}$ in the trough used. The Teflon trough and barriers were cleaned with chloroform and ultrapure water. The Brewster angle microscopy images were captured with a MicroBAM microscope from NIMA-Nanofilm, with lateral resolution of $8 \mu \mathrm{m}$.

As the volume sprayed from the commercial ocular sprays is not well controlled, and in addition the amount sprayed each time is so large, the experiments with control of the volume were done in the following way: several sprays were collected in a vial and the desired volume of the artificial tears was taken with a microsyringe and extended onto the subphase, as usual in Langmuir film formation. Experiments were conducted at room temperature of $23^{\circ} \mathrm{C}$.

\section{Results and discussion}

Fig. $1 \mathrm{~A}$ shows the isotherms obtained spreading $15 \mu \mathrm{L}$ of Innoxa (a), Optrex (b) and Opticalm (c) tears on water subphase. In order to discus the isotherms in more depth, the area in the $\mathrm{X}$-axis has been transformed to area per molecule assuming the 
concentration indicated in the product and that the phospholipid present in the lipid tears is POPC. This is an arbitrary selection but is in accordance with the composition reported previously for lecithin of soya, and the selection of another PC does not significantly change the discussion since the molecular weight is not much different. In the tear composition other surface active compounds are also present (vitamin A and E) but in a much lower concentration, and for that reason they have not been considered in the calculation of the area per molecule. It is seen in Fig. $1 \mathrm{~A}$ that for Innoxa and Optrex tears the initial surface pressure was 0 . On the contrary, the Opticalm tear showed a non-zero initial surface pressure. The isotherm position for Optrex tear is between those of Innoxa and Opticalm, though closer to Innoxa. The characteristic values of the isotherms are shown in Table 2.

Fig. 1B presents the inverse of the compressibility modulus, Eq. (1), for the isotherms of Fig. 1A. This parameter is more suitable to compare the three tears because according to Eq. (1) the use of area or area per molecule does not affect the calculated values of $\mathrm{C}_{s}^{-1}$. In respect to compressibility, Optrex is also closer to Innoxa than to Opticalm. All the tears show low values of $\mathrm{C}_{s}^{-1}$ which corresponds to a liquid expanded state [30], that is, the phospholipids are not organized enough in the film and conserve certain fluidity.

$$
C_{s}^{-1}=-A\left(\frac{d \pi}{d A}\right)_{T}
$$

The collapse is attained as a plateau at surface pressures around $44-49 \mathrm{mN} / \mathrm{m}$. All cycle isotherms present hysteresis when the collapse is reached, but the hysteresis is small if the collapse is not reached or it is just at its beginning (see Fig. S1 in Supplementary Material). Isotherms have also been obtained in a saline subphase $(0.9 \% \mathrm{NaCl}$ concentration, as occurs in natural tears) and no significant influence of this subphase has been observed. Opticalm has a $\mathrm{NaCl}$ concentration lower than that of Innoxa and Optrex, but according to the previous observation the difference observed in the isotherms cannot be due to $\mathrm{NaCl}$. Observing Table 1, a significant difference in composition is that Innoxa and Optrex contain phenoxyethanol, while Opticalm doesn't. Phenoxyethanol is usually used as a preservative and has a certain surface 
activity, but as this compound is not present in Opticalm it cannot be responsible for the higher surface activity of Opticalm.

Fig. 1A. Surface pressure-area isotherms for the lipid-containing tears: a) Innoxa, b) Optrex , c) Opticalm.

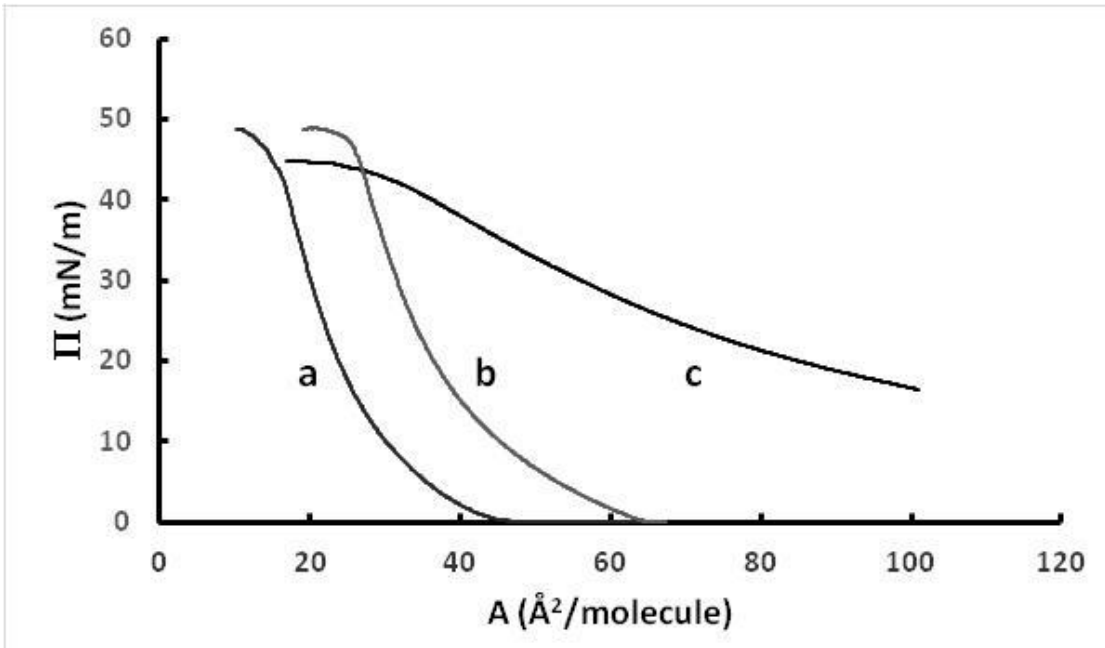

Fig. 1B. Inverse of the compressibility modulus for the isotherms of Fig. 1A.

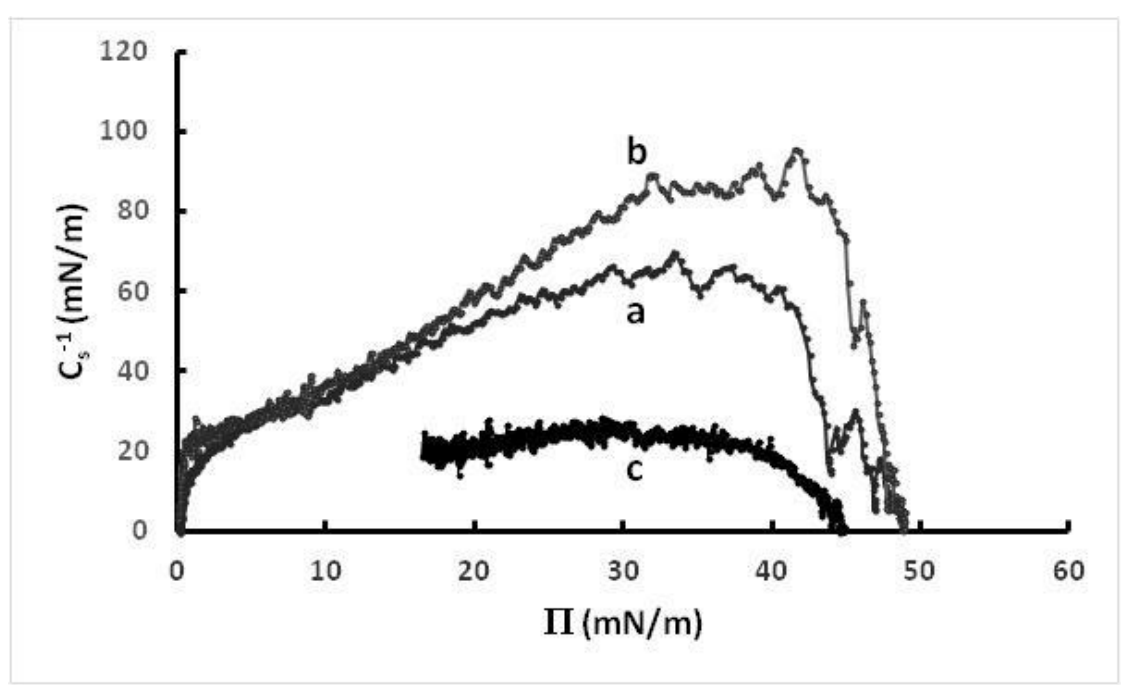

Table 2 shows the values of several isotherm parameters found in literature for several PCs in order to compare these values with those of the isotherms reported here for the lipid-containing tears. Before proceeding to the discussion, a consideration is needed. Even though vitamin $A[35,36]$ and vitamin $E[37,38]$ are surface active, their concentration is low in respect to lecithin (PC), in a ratio lower than $3 \%$, and thus the major contribution is due to PC. In references $[37,38]$ it can be 
seen that the influence of tocopherol (vitamin E) on POPC or E. Coli lipid extracts is small even though tocopherol was present in a molar fraction of 0.25 or 0.20 .

The collapse area observed in all the tear isotherms is less than that of POPC [30] and other PCs (see Table 2) which could indicate that part of the lipid is still in a bilayer state, that is the liposomes present in the product are not completely extended as a monolayer when deposited on the water surface. Thus, the values of $\Pi$ at the collapse and $\mathrm{C}_{s}^{-1}$ can be discussed more confidently than the area values. Another fact that points to the presence of a partial bilayer is that when spreading lower volumes of tear, the lift-off area (expressed in area per molecule) in the isotherm increases or the isotherms shift to higher area per molecule values (see Fig. S2 in Supplementary Material), which is due to a better extension of the liposomes in monolayer. The same fact occurs when the concentration of the components of the tear is reduced by dilution. The values of $\mathrm{C}_{s}^{-1}$ also reinforce this explanation since when reducing the spread tear volume or the concentration, the values of $\mathrm{Cs}_{s}^{-1}$ increase (see later Fig. 2B), indicating a better compactness in the film due to a higher proportion in the monolayer state.

Table 2. Characteristic values from the isotherms of the three lipid-containing tears and of several standard PC phospholipids.

\begin{tabular}{|c|c|c|c|c|c|c|c|}
\hline $\begin{array}{l}\text { Tear or } \\
\text { PC }\end{array}$ & $\begin{array}{l}\text { A lift-off } \\
\AA^{2} / \text { molecule }\end{array}$ & $\begin{array}{l}\text { A collapse } \\
\AA^{2} / \text { molecule }\end{array}$ & $\begin{array}{l}\text { П collapse } \\
\mathrm{mN} / \mathrm{m}\end{array}$ & $\begin{array}{l}\text { A inflexion } \\
\AA^{2} / \text { molecule }\end{array}$ & $\begin{array}{l}\text { П inflexion } \\
\mathrm{mN} / \mathrm{m}\end{array}$ & $\begin{array}{l}\mathrm{C}_{\mathrm{s}}^{-1} \mathrm{max} \\
\mathrm{mN} / \mathrm{m}\end{array}$ & Reference \\
\hline Innoxa & 45 & 12 & 48 & & & 65 & This work \\
\hline Opticalm & $>100$ & 23 & 44 & & & 26 & This work \\
\hline Optrex & 65 & 24 & 49 & & & 89 & This work \\
\hline POPC & 150 & 70 & 46 & & & & 31 \\
\hline DPPC & $90-95$ & 45 & 55 & $75-80$ & $7-8$ & & 28,29 \\
\hline DSPC & 58 & 44 & 55 & & & 334 & 32 \\
\hline SOPC & 112 & 58 & 50 & & & 122 & 32 \\
\hline DOPC & $108-110$ & 55 & 49 & & & 121 & 32 \\
\hline DPPC & $>100$ & $445-50$ & $58-72$ & 90 & $5-6$ & & 33 \\
\hline DOPC & $>100$ & 60 & 48 & & & & 33 \\
\hline DOPC & $130-135$ & 65 & 44 & & & & 34 \\
\hline
\end{tabular}


The values of $\mathrm{C}_{s}^{-1}$ are lower than those reported in literature for some PCs with and without insaturations (Table 2). As all values are lower than that of DOPC, it could also indicate that more insaturations are present in soy PC used for the tear products, and probably the presence of linoleic acid in the PC chains, as is expected from natural soy PC. On the other hand, the values of $\mathrm{C}_{s}^{-1}$ and the isotherm shape suggest that the PCs in Opticalm present more insaturations and are in a more fluid state than in Innoxa or Optrex. This fact possibly indicates the presence of more linoleic acid in C2 in the lecithin present in Opticalm tear, but as the exact nature of the lecithin in commercial products is unknown, it could also indicate the presence of other fluid lipids in the composition.

It is seen that the collapse pressure of Opticalm $(\Pi=44 \mathrm{mN} / \mathrm{m})$ is closer to that of POPC and DOPC (Table 2), in accordance with the presence of more insaturations in PCs of Opticalm than in PCs of Innoxa or Optrex (collapse pressure close to $49 \mathrm{mN} / \mathrm{m}$ ), even the presence of larger chains in the latter is also coherent with the observation. The collapse pressure of the latter is nevertheless lower than those of fully saturated PCs, such as DPPC or DSPC (Table 2), which indicates that a certain degree of insaturation is present in the PC of Innoxa and Optrex. The differences observed between Innoxa and Optrex isotherms, even though the commercial composition is the same, could be due to some differences in the lipid raw material or even some differences in concentration due to different commercial preparation methods of the artificial tears.

BAM images were obtained for the spread tears but the film formed is practically inappreciable and only a few irregular forms can be observed, probably due to aggregates of liposomes (Fig. S3 in Supplementary Material). This could be due to the fact that these lipid tears have refractive indexes similar to water and so no significant reflexion occurs in the Brewster angle of water. On the other hand it is a desirable situation for ocular purposes since the lipid tear film does not disturb the vision process.

As the Opticalm tear shows a non-zero value of initial surface pressure, the amount of spread PC has been reduced in several ways: reducing the concentration by dilution with water, reducing the spread volume or suctioning the film formed in the 
water surface (with a nozzle connected to a vacuum pump) till a lower value or a zero value is obtained for the surface pressure. As in the latter the number of remaining molecules is unknown, the area has been expressed as total area, in $\mathrm{cm}^{2}$ (Fig. 2A). In these situations the shape of the isotherm changes and an inflexion point appears at a surface pressure around $22-28 \mathrm{mN} / \mathrm{m}$. Fig. $2 \mathrm{~B}$ shows the values of $\mathrm{C}_{\mathrm{s}}^{-1}$ for these isotherms. Since the inflexion surface pressure occurs at a high value (compared with the value of DPPC reported in Table 2) and after inflexion the $C_{s}^{-1}$ values are lower (the $\mathrm{C}_{\mathrm{s}}^{-1} \mathrm{max}$ decreases from $40 \mathrm{mN} / \mathrm{m}$ at the first isotherm part to $24 \mathrm{mN} / \mathrm{m}$ at the second one), the most plausible explanation is the formation of a bilayer from a monolayer. As presumably the bilayer obtained in this way is less organized than the monolayer and less compact, the values of $C_{s}^{-1}$ decrease. The tendency to form this bilayer from the monolayer would be in accordance with the previous observation that the lipids present in Opticalm are more fluid, less organized.

Fig. 2A. Surface pressure-area isotherms for the Opticalm tear at different conditions: a) $15 \mu \mathrm{L}$ spread volume, $10 \mathrm{mg} / \mathrm{mL}$ concentration, b) $8 \mu \mathrm{L}$ spread volume, $3.33 \mathrm{mg} / \mathrm{mL}$ concentration, c) layer suctioned till $\Pi=0$.

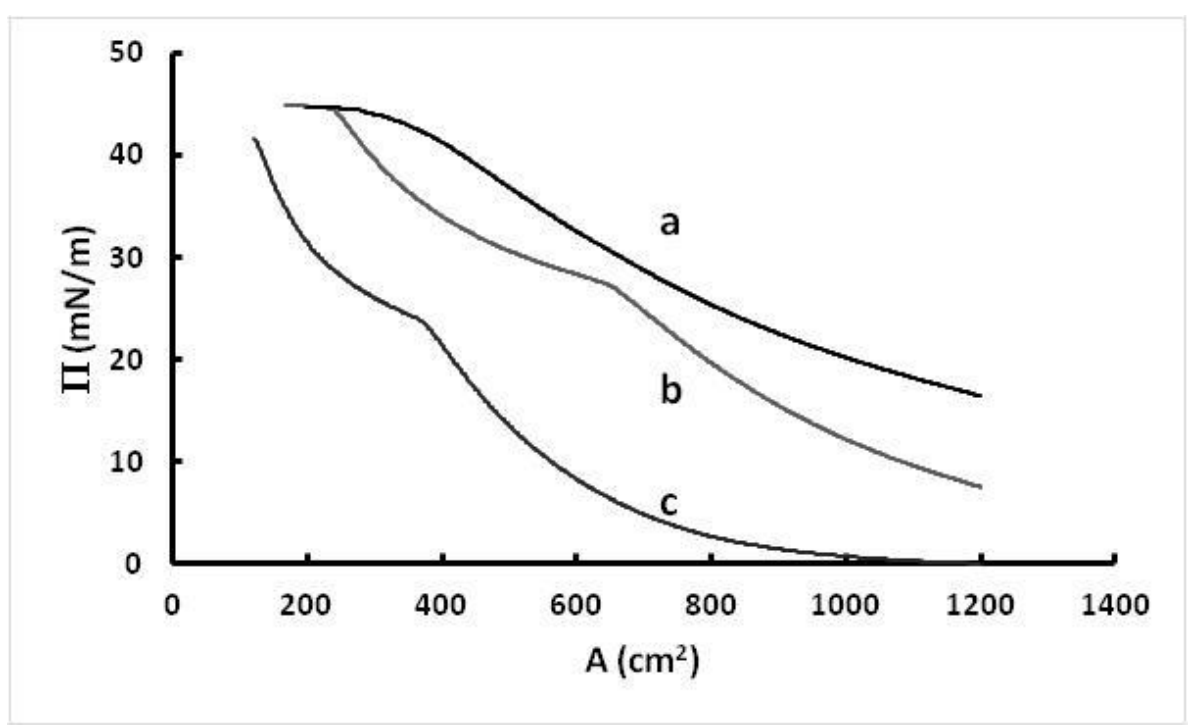


Fig. 2B. Inverse of the compressibility modulus for the isotherms of Fig. 2A.

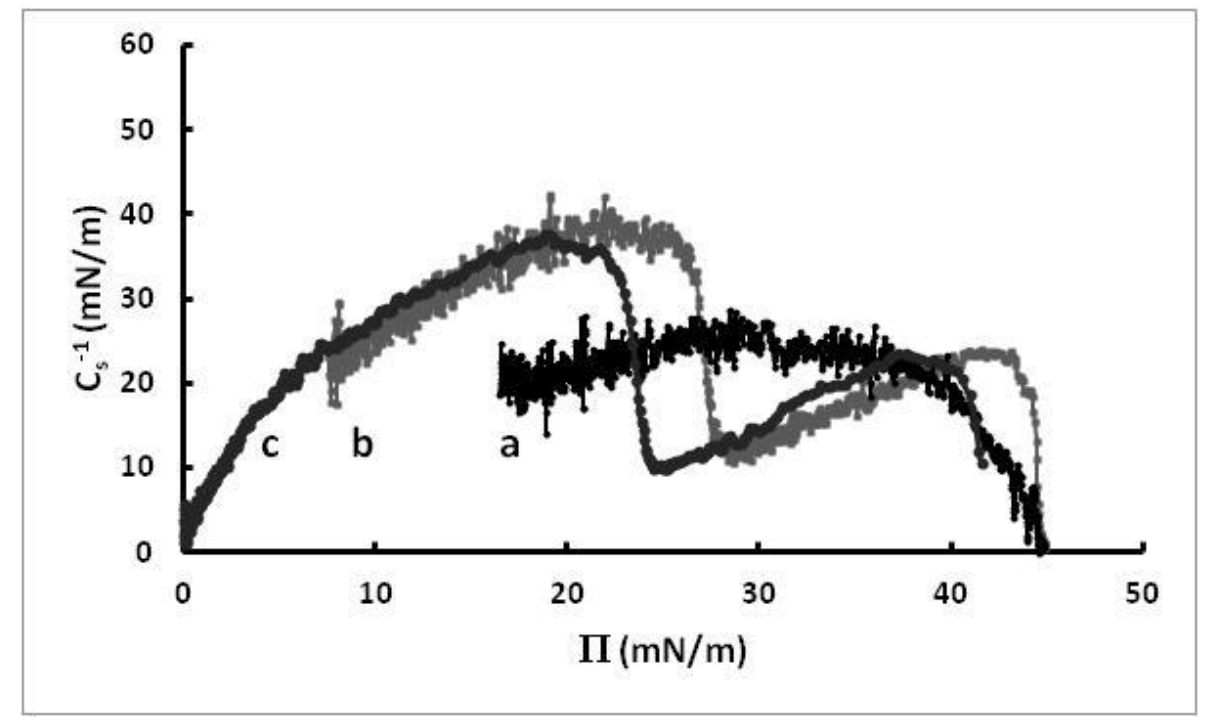

\section{Conclusions}

The lecithin present in the lipid-containing artificial tears studied contains lateral chains with insaturations, more pronounced for the Opticalm tear than for the Innoxa or Optrex tears, that is, the lecithin present in the Opticalm tear probably contains more linoleic acid in the C2 position than the lecithin present in the Innoxa or Optrex tears composition. The Langmuir technique seems useful in order to determine some important parameters, such as the inverse of the compressibility modulus, $\mathrm{Cs}_{s}^{-1}$, and extension at the air-water interface of the lipids contained in the tears, and allows observing differences between commercial lipid-containing tears. The lipid concentration and the spread volume influence the isotherm characteristics.

In the future, it is planned to perform a clinical study using the lipid-containing artificial tears presented here and to try to correlate their clinical behaviour with the film properties reported in this study. In this future work it is also planned to perform experiments at the ocular physiological temperature.

\section{Appendix A. Supplementary data}

Supplementary data associated with this article can be found, in the online version, at 


\section{References}

[1] A. Behrens, J.J. Doyle, R.S. Chuck, Cornea 25 (2006) 900-907.

[2] DEWS 2007, Report of the Dry Eye WorkShop, Ocul. Surf. 5 (2007) 65-204.

[3] DEWS 2011, Report of the Dry Eye WorkShop, Invest. Ophthalmol. Vis. Sci. 52 (2011) 2050.

[4] J. Murube, A. Paterson, E. Murube, Adv. Exp. Med. Biol. 438 (1998) 693-701.

[5] J. Murube, A. Murube, C. Zhuo, Adv. Exp. Med. Biol. 438 (1998) 705-715.

[6] M. Moshirfar, K. Pierson, K. Hanamaikai, L. Santiago-Caban, V. Muthappan, S.F. Passi, Clin. Ophthalmol. 8 (2014) 1419-1433.

[7] U. Benelli, Clin. Ophthalmol. 5 (2011) 783-790.

[8] M.J. Doughty, S. Glavin, Ophthal. Physiol. Opt. 29 (2009) 573-583.

[9] W.H. Ridder III, A. Tomlinson, J. Paugh, Optom. Vision Sci. 82 (2005) 835-842.

[10] N. Mohammad-Reza, R. A. Latkany, M.G. Speaker, Am. J. Ophthalmol. 140 (2005)830-835.

[11] R.B. Grene, P.B.A. Lankston, J.M.S. Mordaunt, M.B.S. M. Harrold, A. Gwon, R. Jones, Cornea 11 (1992) 277-368.

[12] L.C. McCann, A. Tomlinson, E.I. Pearce, V. Papa, Cornea 31 (2012) 1-5.

[13] T-J. Wang, I-J. Wang, J-D. Ho, H-C. Chou, S-Y. Lin, M-C. Huang, Clin. Ther. 32 (2010) 44-52.

[14] C.A. Urzua, D.H. Vasquez, A. Huidobro, H. Hernandez, J. Alfaro, Curr. Eye Res. 37 (2012) 684-688.

[15] J. Nepp, J. Schauersberger, G. Schild, K. Jandrasits, J. Haslinger-Akramian, A. Derbolav, A. Wedrich, Biomaterials 22 (2001) 3305-3310.

[16] R.C. Scaffidi, D.R. Korb, Eye Contact Lens 33 (2007) 38-44.

[17] D.R. Korb, R.C. Scaffidi, J.V. Greiner, K.R. Kenyon, J.P. Herman, C.A. Blackie, T. Glonek, C.L. Case, V.M. Finnemore, T. Douglass, Optom. Vision Sci. 82 (2005) 594-601.

[18] K. Peters, T.J. Millar, Curr. Eye Res. 25 (2002) 55-60.

[19] T. Kaercher, D. Hönig, D. Möbius, Internat. Ophthalmol. 17 (1993) 341-348.

[20] T. Kaercher, D. Hönig, D. Möbius, Orbit 14 (1995) 17-24.

[21] S. Hagedorn, E. Drolle, H. Lorentz, S. Srinivasan, Z. Leonenko, L. Jones, J. Optom. 8 (2015) 187-199. 
[22] P.G. Petrov, J.M. Thompson, I.B. Abdul Rahman, R.E. Ellis, E.M. Green, F. Miano, C.P. Winlove, Exp. Eye Res. 84 (2007) 1140-1146.

[23] P. Mudgil, T.J. Millar, Invest. Ophthalmol. Vis. Sci. 52 (2011) 1661-1670.

[24] F. Miano, M. Calcara, T.J. Millar, V. Enea, Colloids Surf. B 44 (2005) 49-55.

[25] P. Mudgil, M. Torres, T.J. Millar, Colloids Surf. B 48 (2006) 128-137.

[26] P. Mudgil, T.J. Millar, Exp. Eye Res. 86 (2008) 622-628.

[27] T.J. Millar, P. Mudgil, I.A. Butovich, C.K. Palaniappan, Invest. Ophthalmol. Vis. Sci. 50 (2009) 140-151.

[28] J. Torrent-Burgués, BioNanoSci. 1 (2011) 202-209.

[29] J. Hoyo, J. Torrent-Burgués, E. Guaus, J. Colloid Interf. Sci. 384 (2012) 189-197.

[30] P. Vitovič, D.P. Nikolelis, T. Hianik, Biochim. Biophys. Acta 1758 (2006) 1852-1861.

[31] O. Domenech, J. Torrent-Burgués, S. Merino, F. Sanz, M.T. Montero, J. HernandezBorrell, Colloids Surf. B 41 (2005) 233-238.

[32] P. Dynarowicz-Łatka, K. Haç-Wydro, Colloids Surf. B 37 (2004) 21-25.

[33] W. Yan, B. Piknova, S.B. Hall, Biophys. J. 89 (2005) 306-314.

[34] C. Yuan, J. Furlong, P. Burgos, L.J. Johnston, Biophys. J. 82 (2002) 2526-2535.

[35] C.P. de Melo, M.I. Mosquera-Sánchez, Langmuir 14 (1998) 490-496.

[36] N. Kimura, K. Imai, T. Sawada, Thin Solid Films 438-439 (2003) 414-417.

[37] M. Broniatowski, M. Flasinski, K. Haç-Wydro, Biochim. Biophys. Acta 1848 (2015) 2154-2162.

[38] M. Jurak, J. Miñones Conde, Biochim. Biophys. Acta 1828 (2013) 2410-2418. 


\section{Supplementary data}

Fig. S1. Surface pressure-area isotherm cycles for lipid-containing artificial tears.

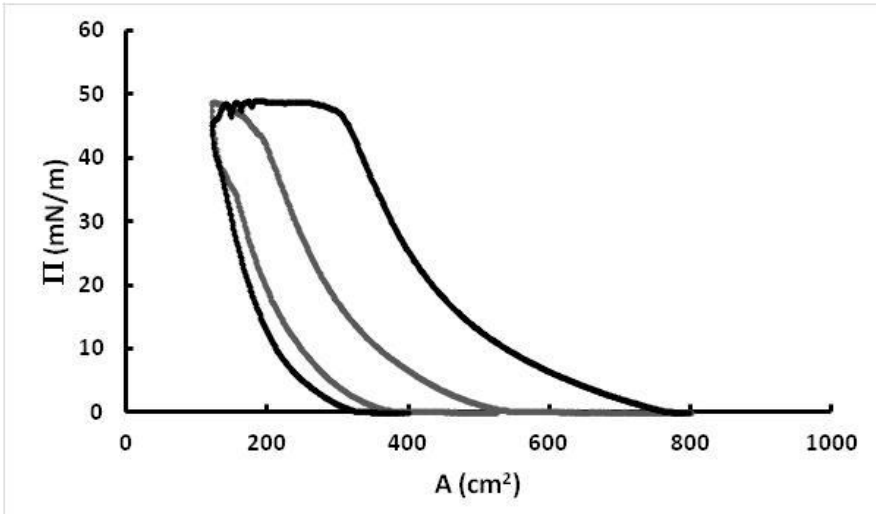

Fig. S2. Surface pressure-area per molecule isotherms for the Opticalm tear at different conditions: a) $15 \mu \mathrm{L}$ spread volume, $10 \mathrm{mg} / \mathrm{mL}$ concentration, b) $8 \mu \mathrm{L}$ spread volume, $3.33 \mathrm{mg} / \mathrm{mL}$ concentration.

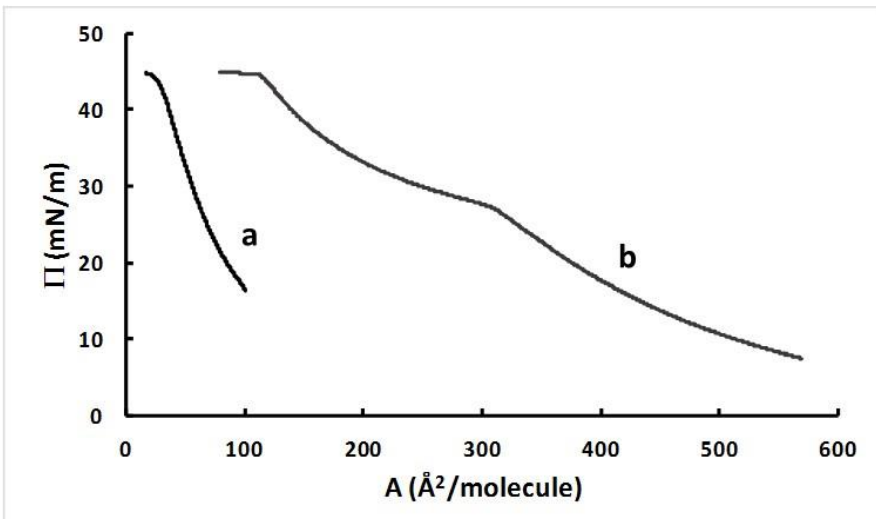

Fig. S3. BAM image $(3.6 \mathrm{~mm} \times 4.1 \mathrm{~mm})$ for a lipid-containing artificial tear extended on water.

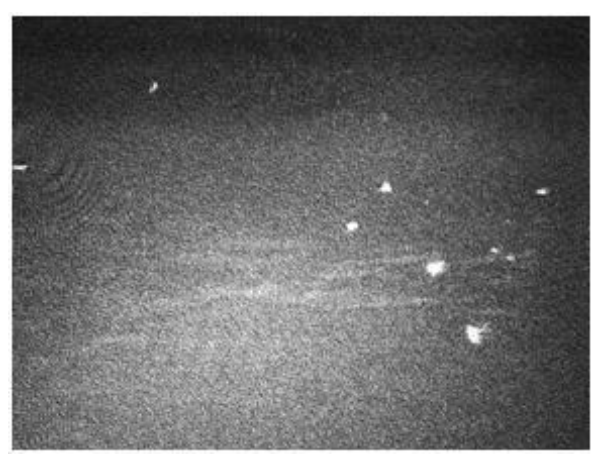

